\title{
Familial sinus node dysfunction with autosomal dominant inheritance
}

\author{
H. LEHMANN AND U. E. KLEIN \\ From the Department of Internal Medicine and Cardiology, University of Kiel, Kiel, Federal Republic \\ of Germany
}

SUMMARY A large family with sinus node dysfunction is described, spanning three generations and with an autosomal dominant trait. There was an obvious association between the grade of mental retardation and the severity of the sinoatrial disorder.

Recently, the high prevalence of systemic embolism in chronic sinoatrial disorders or so-called 'sick sinus syndrome' has been stressed (Fairfax et al., 1976). In their series of 100 patients with this syndrome, only 2 cases were familial. A few familial cases were also reported in other series of patients with the sick sinus syndrome (Rokseth et al., 1970; Rokseth and Hatle, 1974) and it appears that approximately 2 to 6 per cent of cases are inherited. There are already 4 extensive reports on family pedigrees showing this syndrome to be an autosomal trait in one to three generations (Spellberg, 1971; Livesley et al., 1972; Caralis and Varghese, 1976; Jagovella et al., 1976). We report on a very large family with chronic sinoatrial disorders occurring in three generations. Some of the members of the family died suddenly and had had mental retardation as well as sinus node dysfunction. In one woman with the tachycardia-bradycardia syndrome, tachycardia was induced by emotional stimuli and it was necessary to implant a permanent pacemaker.

\section{Case report and family history (Fig.)}

A 37-year-old woman was admitted to our intensive care unit immediately after delivery of her seventh child, with a life-endangering tachycardia-bradycardia syndrome and recurrent atrial fibrillation. The patient was of poor intelligence and had no understanding of her disease. The tachycardia could be repeatedly triggered by slight psychological stress and treated by reassurance. We finally installed an endocardial pacemaker system and also treated her with digitalis and sedatives. Four days later a severe pulmonary embolism occurred, from which she recovered slowly. Her condition then improved greatly and she was able to look after her home and 7 children.

Her mother, who gave birth to 11 children, had had a cardiac arrhythmia from childhood and died of sudden cardiac arrest. Early electrocardiograms showed sinus bradycardia $(35 / \mathrm{min})$, and later records also showed atrial fibrillation.

Three brothers had persistent atrioventricular dissociation. One of the brothers with atrioventricular dissociation also had second degree atrioventricular block and died unexpectedly at the age of 38. Necropsy showed no cardiomegaly and no evidence of cardiomyopathy or severe coronary heart disease (heart weight $550 \mathrm{~g}$ ). Another brother had repeated episodes of loss of consciousness, though his electrocardiogram showed only incomplete right bundle-branch block at rest. One sister had atrioventricular dissociation and intermittent 2:1 atrioventricular block. Two brothers and one sister died in infancy of unknown cause, one brother was not examined, and one sister was in good health.

Of the 7 children of our patient, 4 have inter. mittent sinoatrial or atrioventricular block, with attacks of dizziness.

An association was observed between the arrhythmia and mental retardation in the children, and 3 brothers were also mentally retarded.

\section{Discussion}

Inherited sinus node dysfuction is not specifically mentioned but its presence can be inferred in numerous reports of pedigrees of patients with multiform arrhythmias. Some members of these 


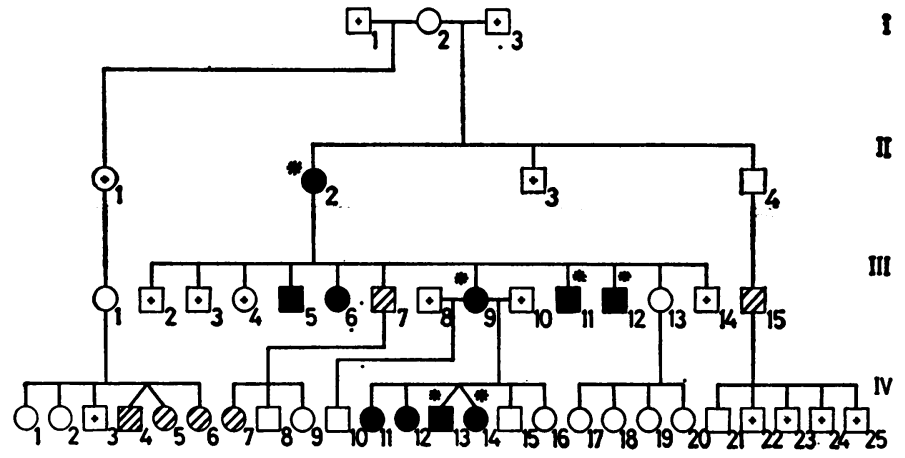

1

III

Fig. Pedigree of family with inherited autosomal dominant sick sinus syndrome.

$\bigcirc$ normal electrocardiogram, $\square$ electrocardiogram showing features of sick sinus syndrome $\left({ }^{\star}\right)$ or $A V$ heart block,

$\oslash$ minor electrocardiographic abnormalities without specific features of sick sinus syndrome, $\odot$ no electrocardiogram.

I. $3=$ muscular dystrophy of shoulder girdle type.

II. $2=$ sinus bradycardia (35/min), later atrial fibrillation.

III. 5, 6 = atrioventricular dissociation, second degree atrioventricular block (III. 5 sudden death).

III. $7 \quad$ incomplete right bundle-branch block, syncopal attacks.

III. $9=$ sinus bradycardia (35/min), with atrial fibrillation and paroxysmal ventricular tachycardia.

III. 11,12 = atrioventricular dissociation.

III. $15=$ sinus bradycardia (less than $50 / \mathrm{min}$ ).

IV. $4,5,6,7=$ sinus bradycardia (less than $50 / \mathrm{min}$ ).

IV. $11=$ intermittent second degree atrioventricular block $(3: 1)$.

IV. $12=$ intermittent second degree atrioventricular block $(2: 1)$.

IV. $13=$ episodes of sinus arrest.

IV. $14=$ episodes of sinus arrest, intermittent second degree atrioventricular block $(2: 1)$.

families showed persistent atrial standstill, sinus bradycardia, atrial fibrillation, atrioventricular nodal rhythm with atrioventricular dissociation, or complete heart block (Bacos et al., 1960; Phair, 1963; Khorsandian et al., 1964; Gazes et al., 1965; Allensworth et al., 1969; Gault et al., 1972). Electrocardiograms of first degree relatives of unselected patients with complete atrioventricular block have been examined and conduction abnormalities found in 10 per cent (Morgans et al., 1974). Family screening thus appears to be desirable in cases of aetiologically unexplained disorders of heart rhythm and also after unexpected death in young adults.

In the family described here, the sinoatrial disorders were already evident in childhood. The evolution from sinus bradycardia to atrial fibrillation and sudden death was documented in the mother.

The exact cause of familial sick sinus syndrome is unknown. In some cases, morphological changes in the sinus node artery (James, 1967), sinus node fibrosis, or necrosis of atrial cells (Allensworth et al., 1969) have been observed. In a large series of patients with the sick sinus syndrome, however, there were no striking alterations of the sinus node artery, at least angiographically (Engel et al., 1975).
An enzyme deficiency has been postulated, but such 'inborn errors of metabolism' are usually recessive traits, whereas familial heart arrhythmias are autosomally dominant. Familial muscle dystrophies have also been associated with the sick sinus syndrome, and our patient's maternal grandfather suffered from muscular dystrophy with onset in the shoulder girdle. None of his offspring, however, showed any evidence of muscle disease.

Caralis and Varghese (1976) recently put forward the suggestion that an increase in vagal tone may be responsible for familial sinus node dysfunction. Thus, these patients may be hypersensitive to normal phasic vagal stimulation (Dighton, 1975). This hypothesis is supported by one case of sick sinus syndrome in a family with prolonged PR interval (Gambetta et al., 1973). On the other hand, patients with the familial QT prolongation syndromes with and without deafness (JervellLange-Nielsen syndrome, Romano-Ward syndrome) may have a reduced sympathetic tone. An altered sympathetic nerve response unrelated to the heart has also been reported (Ziegler et al., 1976). If this dysfunction of the autonomic nervous system affecting vagal and/or sympathetic tone is a possible explanation, then familial sick sinus syndrome may 
be the result of either nodal hypersensitivity to normal phasic stimulation (as in our patient) or overstimulation ('vagal epilepsy') caused by an unstable cerebral focus. Lown et al. (1976) gave an excellent description of a case showing ventricular fibrillation caused by emotionally determined sympathetic nervous discharge. Similarly, the lifethreatening tachycardias in our patient were obviously influenced by psychological factors.

Because of the possibility that a familial dysfunction of sympathetic or vagal tone may be a cause of cardiac arrhythmias, the use of psychotropic drugs and psychotherapy should be considered in these cases. In addition, when discussing the genesis of rhythm disorders in an individual patient, one should consider personal, psychological, and genetic factors.

\section{References}

Allensworth, D. C., Rice, C. J., and Lowe, G. W. (1969). Persistent atrial standstill in a family with myocardial disease. American fournal of Medicine, 47, 775-784.

Bacos, J. M., Eagan, J. T., and Orgain, E. S. (1960). Congenital familial nodal rhythm. Circulation, 22, 887-895.

Caralis, D. G., and Varghese, P. J. (1976). Familial sinoatrial node dysfunction. British Heart fournal, 38, 951-956.

Dighton, D. H. (1975). Sinoatrial block, autonomic influences and clinical assessment. British Heart fournal, 37, 321-325.

Engel, T. R., Meister, S. G., Feitosa, G. S., Fischer, H. A., and Frankl, W. (1975). Functional appraisal of sinus node artery disease (abstract). American Fournal of Cardiology, 35, 135.

Fairfax, A. J., Lambert, C. D., and Leatham, A. (1976). Systemic embolism in chronic sinoatrial disorder. New England fournal of Medicine, 295, 190-192.

Gambetta, M., Weese, J., Ginsburg, M., and Shapiro, D. (1973). Sick sinus syndrome in a patient with familial PR prolongation. Chest, 64, 520-523.
Gault, J. H., Cantwell, J., Lev, M., and Braunwald, E. (1972). Fatal familial cardiac arrhythmias; histologic observations on the cardiac conduction system. American fournal of Cardiology, 29, 548-553.

Gazes, P. C., Culler, R. M., Taber, E., and Kelly, T. E. (1965). Congenital familial cardiac conduction defects. Circulation, 32, 32-34.

Jacovella, G., Santini, M., Floris, B., and Masini, V. (1976). Malattia del nodo del seno familiare; Osservazioni su tre casi personali. Giornale Italiano di Cardiologia, 6, 112-117.

James, T. M. (1967). Congenital deafness and cardiac arrhythmias. American fournal of Cardiology, 19, 627-643.

Khorsandian, R. S., Moghadam, A. N., and Müller, O. F. (1964). Familial congenital av-dissociation. American Fournal of Cardiology, 14, 118-124.

Livesley, B., Catley, P. F., and Oram, S. (1972). Familial sinuatrial disorder. British Heart fournal, 34, 668-670.

Lown, B., Temte, J. V., Reich, P., Gaughan, C., Regestein, Q., and Hai, H. (1976). Basis for recurring ventricular fibrillation in the absence of coronary heart disease and its management. New England fournal of Medicine, 294, 623-629.

Morgans, C. M., Gray, K., and Robb, G. H. (1974). A survey of familial heart block. British Heart fournal, 36, 693-696.

Phair, W. B. (1963). Familial atrial fibrillation. Canadian Medical Association fournal, 89, 1274-1276.

Rokseth, R., and Hatle, L. (1974). Prospective study on the occurrence and management of chronic sinoatrial disease, with follow up. British Heart Fournal, 36, 582-587.

Rokseth, R., Hatle, L., Gedde-Dahl, D., and Foss, P. O. (1970). Pacemaker therapy in sinoatrial block complicated by paroxysmal tachycardia. British Heart fournal, 32, 93-98.

Spellberg, R. D. (1971). Familial sinus node disease. Chest, 60, 246-251.

Ziegler, M. G., Lake, R., and Kopin, I. J. (1976). Deficient sympathic nervous response in familial dysautonomia. New England fournal of Medicine, 294, 630-633.

Requests for reprints to $\operatorname{Dr} H$. Lehmann, First Department of Medicine, University of Kiel, Schittenhelmstr. 12, $2300 \mathrm{Kiel}$, West-Germany. 